\title{
Sistem Pendukung Keputusan Untuk Penentuan Dosen Favorit Menggunakan Simple Additive Weighting (SAW)
}

\author{
Wowon Priatna ${ }^{1}$, Agung Nugroho ${ }^{2}$, Nurjeli ${ }^{3}$ \\ Universitas Bhayangkara, STT Pelita Bangsa, STMIK Mitra Karya \\ wowon.priatna@dsn.ubharajaya.ac.id, agung@pelitabangsa.ac.id, elhyho19@gmail.com
}

\begin{abstract}
The process of determining favorites is what must be in accordance with predetermined criteria. To help in selecting people who deserve to be favorites, a decision support system is needed. One method that can be used to support decisions is to use FMADM (Fuzzy Multiple Addictive Decision Making). Where in this study using the SAW method (Simple Addictive Weighted), which is to find the best alternative from several alternatives. Find the best alternative based on predetermined criteria. This method is chosen to choose the best alternative that is suitable, and look for the value of each attribute, after the search process to get the best.
\end{abstract}

Keywords: information System, Decision support system, fuzzy SAW, FMADM

\begin{abstract}
Abstrak
Proses penentuan dosen favorit yaitu harus sesuai dengan kriteria yang telah ditentukan. Untuk membantu dalam menseleksi penentuan seseorang yang layak menjadi dosen favorit, maka dibutuhkan sebuah sistem pendukung keputusan. Salah satu metode yang dapat digunakan untuk sistem pendukung keputusan yaitu menggunakan FMADM (Fuzzy Multiple Addective Decission Making). Dimana pada penelitian ini menggunakan metode SAW (Simple Addictive Weighted) yaitu mencari alternatif terbaik dari beberapa alternatif. Dimana alternatif terbaik berdasarkan kriteria-kriteria yang telah ditentukan. Metode ini dipilih karna mampu memilih alternatif terbaik yaitu dosen terbaik berdasarkan kriteria yang dimasukkan, kemudian mencari nilai bobot dari setiap atribut, setelah proses mencari perangkingan untuk mendapatkan alternatif terbaik yaitu dosen favorit.
\end{abstract}

Kata kunci: Sistem InformasiSistem pendukung Keputusan, FMADM, fuzzy SAW, Kriteria Dosen Favorit

\section{PENDAHULUAN}

Memiliki dosen atau staff pengajar yang disukai oleh mahasiswa adalah keharusan dalam menciptakan proses belajar yang nyaman dan kelancaran di kelas yang membuat mahasiswa akan semangat mengikuti proses perkuliahan sehingga terciptanya proses belajar yang lebih efektif. Untuk menjadi seorang dosen favorit tidaklah mudah untuk dijalani. Tidak hanya harus kuliah tinggi-tinggi dan memiliki otak yang cemerlang, dosen harus bisa mengambil hati para mahasiswanya agar mereka mampu menyerap mata kuliah yang disampaikannya. 
STMIK Mitra Karya merupakan lembaga pendidikan yang selalu berupaya untuk meningkatkan kualitas dalam proses pembelajaran sehingga dapat menghasilkan lulusan yang mempunyai kompetensi di bidangnya, untuk itu STMIK Mikar menentukan pemilihan dosen favorit hal ini di lakukan untuk memotivasi dosen lebih meningkatkan kualitas dan kompetensinya. kompetensi yang ada. Dalam penentuan dosen favorit di STMIK Mitra Karya terdapat beberapa faktor yang menjadi penilaian kinerja, adalah keterlibatan dosen dalam sekolah tinggi meliputi pelaksaan proses belajar mengajar, kuisoner, bimbingan, penelitian dan pengabdian pada masyarakat. Didalam era teknologi seperti ini dibutuhakan suatu system pengambil keputusan untuk mendapatkan sistem PendukungKeputusan sebagai sekumpulan tools komputer yang terintegrasi yang mengijinkan seorang decision maker untuk berinteraksi langsung dengan komputer.

Dari uraian masalah di atas, maka perlu adanya sebuah sistem pendukung keputusan yang dapat membantu proses pengambilan keputusan suatu masalah sehingga keputusan yang diberikan atau dihasilkan diharapkan dapat memenuhi batasan yang ditentukan. Dalam penelitian ini menggunakan Metode SAW karena metode ini menentukan bobot dan kriteria seperti penelitian yang telah dilakukan Sihombing Hutasoit dkk[6] merancang sistem pendukung keputusan untuk melakukan penilaian guru terbaik menggunakan metode SAW, sedangkan Hidayat dkk[4] menggunakan metode SAW untuk mengukur kinerja dosen di universitas muhamadiyah solo. Sedangkan Fitriyania[3] menggunakan SAW untuk menentukan beasiswa. Afshari dkk[1] SAW digunakan untuk menyelesaikan seleksi permasalahan.

\section{METODOLOGI PENELITIAN}

\subsection{Analisis Data}

Data yang didapatkan dianalisa sesuai dengan Konsep dasar metode SAW adalah mencari penjumlahan terbobot dari rating kinerja pada setiap alternatif pada semua atribut. Metode SAW membutuhkan proses normalisasi matriks keputusan $(\mathrm{X})$ ke suatu skala yang dapat diperbandingkan dengan semua rating alternatif yang ada. Metode SAW adalah salah satu metode untuk menyelesaikan permasalahan dalam FMADM [1][11] Metode SAW membutuhkan proses normalisasi matriks keputusan (X) ke suatu skala yang dapat diperbandingkan dengan semua rating alternatif yang ada.

Fuzzy Multiple Attribute Decision Making (FMADM) adalah suatu metode yang digunakan untuk mencari alternatif optimal dari sejumlah alternative dengan kriteria tertentu. Inti dari FMADM adalah menentukan nilai bobot untuk setiap atribut, kemudian dilanjutkan dengan proses perangkingan yang akan menyeleksi alternatif yang sudah[7][2][5][8]. 
Langkah-langkah dalam metode SAW adalah [7]:

1. Membuat matrik keputusan $\mathrm{R}$ berukuran $\mathrm{m} \times \mathrm{n}$, dimana alternatif yang dipilih dan $\mathrm{n}=$ kriteria.

2. Memberikan nilai $X$ setiap alternatif (i) pada setiap kriteria (j) yang sudah ditentukan, dimana, $\mathrm{i}=1,2, \ldots \mathrm{m}$ dan $\mathrm{j}=1,2, \ldots \mathrm{n}$ pada matrik keputusan R.

$$
R=\left[\begin{array}{ccccc}
x_{11} & x_{12} & x_{13} & \ldots & x_{1 n} \\
x_{21} & x_{22} & x_{23} & \ldots & x_{2 n} \\
x_{31} & x_{32} & x_{33} & \ldots & x_{3 n} \\
\ldots & \ldots & \ldots & \ldots \ldots \ldots \ldots \ldots \ldots \\
x_{m 1} & x_{m 2} & x_{m 3} & \ldots & x_{m n}
\end{array}\right]
$$

3. Memberikan nilai bobot preferensi (W) oleh pengambil keputusan untuk masing masing kriteria yang sudah ditentukan.

4. Melakukan normalisasi matrik keputusan $\mathrm{R}$ dengan cara menghitung nilai rating kinerja ternormalisasi (rij ) dari alternatif pada atribut $\mathrm{Cj}$.

$$
r_{i j}= \begin{cases}\frac{x_{i j}}{M a x_{i} x_{i j}} & j i k a \text { jadalah atribut keuntungan (benefit) } \\ \frac{\operatorname{Min} x_{i j}}{x_{i j}} & \text { jika jadalah atribut biaya (cost) }\end{cases}
$$

5. Hasil dari rating kerja ternormalisasi (2010) membentuk matrik ternormalisasi (Z).

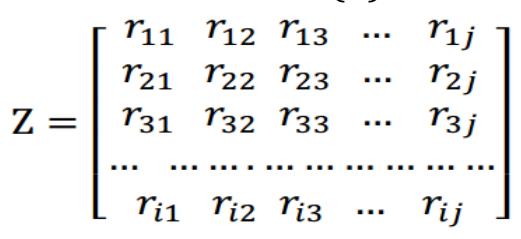

6. Menentukan nilai preferensi untuk setiap alternatif (V) dengan cara menjumlahkan hasil kali antara matrik ternormalisasi (Z) dengan nilai bobot preferensi (W).

$$
V_{i}=\sum_{j=1}^{n} w_{j} r_{i j}
$$

\subsection{Penerapan SAW}

Berikut adalah tahapan-tahapan dalam penerapan SAW.

1. Pembobotan

Untuk menentukan Dosen Favorit tahap pertama yang dilakukan adalah dengan menentukan kriteria penilaian dan bobot dari masing-masing kriteria. 


\section{Menentukan nilai matrix}

Membuat matrik keputusan $\mathrm{R}$ berukuran $\mathrm{m} \times \mathrm{n}$ yang didapat dari hasil pembobotan.

3. Menentukan matrix keputusan

Skor yang sudah diinput selanjutnya dilakukan perhitungan normalisasi (R) dengan menggunakan formula yang sesuai dengan jenis atribut kriteria.

4. Perhitungan preferensi (Vi)

Perhitungan preferensi bisa dilakukan apabila proses normalisasi telah selesai dan sudah diketahui hasilnya. Setelah itu semua hasil normalisasi dimasukan ke dalam rumus Preferensi (Vi).

\section{HASIL DAN PEMBAHASAN}

\subsection{Impementasi SAW}

a. Menentukan Bobot kriteria

Dalam menentukan dosen favorit diperlukan bobot kriteria yang digunakan. Dilihat pada table 1.

Tabel 1. Bobot Kriteria

\begin{tabular}{|c|l|c|c|}
\hline Kode & \multicolumn{1}{|c|}{ Kriteria } & Bobot & Keterangan \\
\hline C1 & Pandangan Luas & 0,4 & Benefit \\
\hline C2 & Mudah Dihubungi & 0,25 & Benefit \\
\hline C3 & Pinter & 0,15 & Benefit \\
\hline C4 & Tidak Pelit Nilai & 0,1 & Benefit \\
\hline C5 & Tidak Pelit Ilmu & 0,1 & Benefit \\
\hline \multicolumn{2}{|c|}{ Total } & 1 & \\
\hline
\end{tabular}

b. Menentukan nilai matrik

Skor nilai matriks diperoleh dari hasil perhitungan masing-masing kriteria. Perhitungan ini dasar untuk menentukan nilai normalisasi (R) dan nilai preferensi (Vi). input nilai matriks dapat dilihat pada tabel 2.

Tabel 2. Input nilai matrix

\begin{tabular}{|l|c|c|c|c|c|}
\hline \multirow{2}{*}{ Kriteria } & \multicolumn{5}{c|}{ Nama Dosen } \\
\cline { 2 - 6 } & A1 & A2 & A3 & A4 & A5 \\
\hline Pandangan Luas & 91 & 70 & 90 & 80 & 85 \\
\hline Mudah Dihubungi & 88 & 80 & 85 & 70 & 75 \\
\hline Pintar & 86 & 75 & 70 & 80 & 80 \\
\hline Tidak Pelit Nilai & 84 & 80 & 90 & 90 & 80 \\
\hline Tidak Pelit Ilmu & 84 & 95 & 75 & 95 & 90 \\
\hline
\end{tabular}

Nilai skor di input pada tabel diatas pada tiap-tiap kriteria C1, C2, C3, C4, C5 sudah dalam bentuk nilai matriks awal. Nilai matrix awal dapat dilihat pada tabel 3 . 
Tabel 3. Nilai Matrix Awa

\begin{tabular}{|c|c|c|c|c|c|}
\hline \multirow{2}{*}{ Alternatif } & \multicolumn{5}{|c|}{ Kriteria } \\
\cline { 2 - 6 } & C1 & C2 & C3 & C4 & C5 \\
\hline A1 & 91 & 88 & 86 & 84 & 84 \\
\hline A2 & 70 & 80 & 75 & 80 & 95 \\
\hline A3 & 90 & 85 & 70 & 90 & 75 \\
\hline A4 & 80 & 70 & 80 & 90 & 95 \\
\hline A5 & 85 & 75 & 80 & 80 & 90 \\
\hline
\end{tabular}

c. Menentukan Matriks R (Normalisasi)

Skor yang sudah diinput selanjutnya dilakukan perhitungan normalisasi (R) dengan menggunakan formula yang sesuai dengan jenis atribut kriteria penilaian, karena pada kasus ini semua kriteria atribut bersifat benefit maka digunakan formula (2). Hasil dari matrix R normalisasi dapat dilihat pada tabel 4 .

Tabel 4. Hasil Normalisasi

\begin{tabular}{|c|c|c|c|c|c|}
\hline \multirow{2}{*}{ Alternatif } & \multicolumn{5}{|c|}{ Kriteria } \\
\cline { 2 - 6 } & C1 & C2 & C3 & C4 & C5 \\
\hline A1 & 1 & 1 & 1 & 0,93 & 0,88 \\
\hline A2 & 0,76 & 0,9 & 0,87 & 0,88 & 1 \\
\hline A3 & 0,98 & 0,96 & 0,81 & 1 & 0,78 \\
\hline A4 & 0,87 & 0,79 & 0,93 & 1 & 1 \\
\hline A5 & 0,93 & 0,85 & 0,93 & 0,88 & 0,94 \\
\hline
\end{tabular}

d. Perhitungan preferensi (Vi)

Setelah itu semua hasil normalisasi dimasukan ke dalam rumus Preferensi (Vi) yaitu dengan formula (3) sebagai dengan ketentuan bobot $(\mathrm{W})=[0,40,250,150,10,1]$. Untuk mendapatkan preferensi (Vi), maka setiap kolom alternatif ternormalisasi dikalikan dengan bobot yang telah ditentukan sebelumnya. Hasil perhitungan ditunjukan pada tabel 5.

Tabel 5. Nilai preferensi

\begin{tabular}{|l|c|}
\hline \multicolumn{1}{|c|}{ Alternatif } & Nilai Preferensi \\
\hline V5 $=A 5$ & 0,906 \\
\hline V4=A4 & 0,885 \\
\hline V3=A3 & 0,9315 \\
\hline V2=A2 & 0,8475 \\
\hline V1=A1 & 0,621 \\
\hline
\end{tabular}

Dan setelah dilakukan perankingan sehingga didapatkan hasil pada tabel 6. 
Tabel 6. Hasil Rangking

\begin{tabular}{|l|c|c|}
\hline \multicolumn{1}{|c|}{ Alternatif } & Nilai Preferensi & Rangking \\
\hline V5 =A5 & 0,906 & 1 \\
\hline V4=A4 & 0,885 & 2 \\
\hline V3=A3 & 0,9315 & 3 \\
\hline V2=A2 & 0,8475 & 4 \\
\hline V1=A1 & 0,621 & 5 \\
\hline
\end{tabular}

Dari hasil perhitungan preferensi yang telah diranking maka hasilnya adalah V5 atau A5 memiliki nilai tertinggi, dan hasil ini bisa digunakan sebagai pendukung keputusan dalam penentuan dosen favorit di STMIK MIKAR.

\subsection{Perancangan Sistem}

Untuk perancangan system di modelkan mengunakan use case dan class diagram yang merupakan diagram UML (Unified modeling Language) yang berfungsi memodelkan user yang berinteraksi dengan system. Digram use case dan class diagram untuk system pendukung keputusan menentukan dosen favorit ditunjukan pada gambar 1 dan gambar 2 .

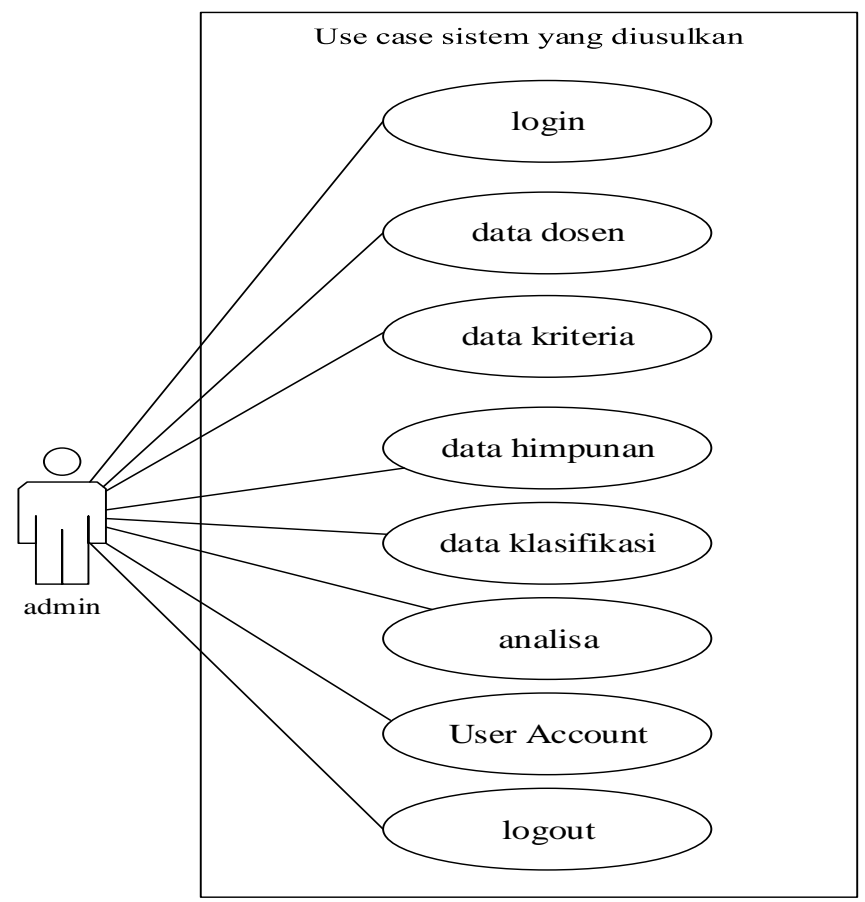

Gambar 1. Use Case Diagram 
Jurnal Riset Sistem Informasi Dan Teknik Informatika (JURASIK)

Volume (4) Juli 2019, pp 181-190

ISSN: 2527-5771/EISSN: 2549-7839

http://tunasbangsa.ac.id/ejurnal/index.php/jurasik

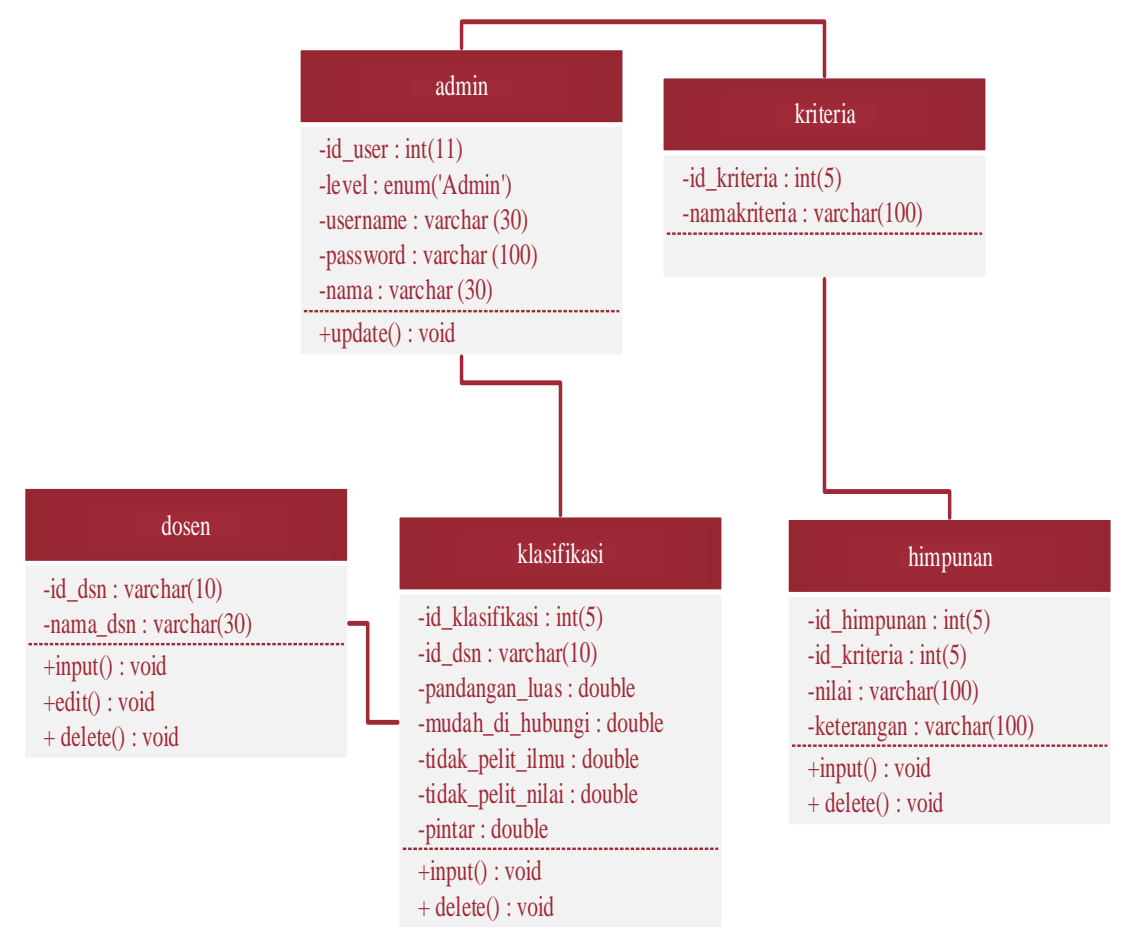

Gambar 2. Class Diagram

\subsection{Hasil Perancangan Aplikasi}

Berikut adalah gambar 3 adalah tampilan menu awal aplikasi system pemilihan keputusan dosen Pavorit

a. Menu Utama

Halaman menu utama berfungsi sebagai halaman awal sebuah sistem setelah login dan sebagai penghubung antara menu yang satu dengan menu yang lain.

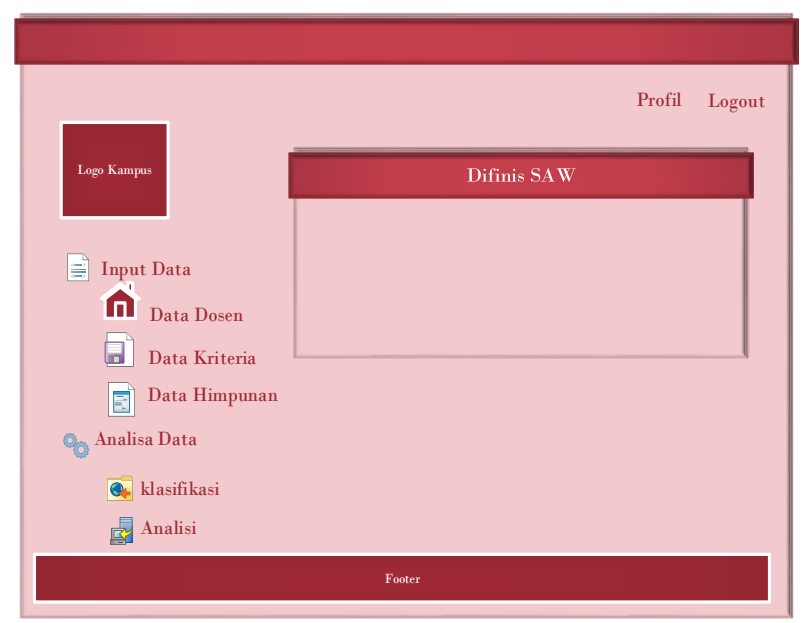

Gambar 3. Halaman Utama Aplikasi 
Jurnal Riset Sistem Informasi Dan Teknik Informatika (JURASIK)

Volume (4) Juli 2019, pp 181-190

ISSN: 2527-5771/EISSN: 2549-7839

http://tunasbangsa.ac.id/ejurnal/index.php/jurasik

b. Halaman Profil admin.

Halaman profil berfungsi sebagai halaman untuk merubah data profil

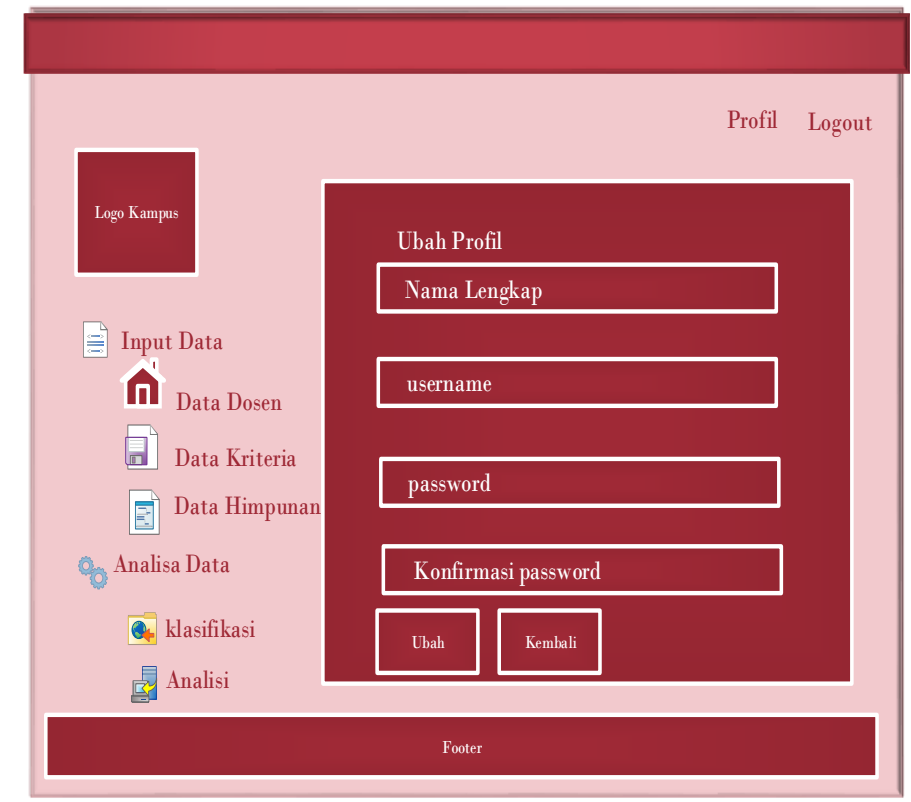

Gambar 4. Halaman profil

c. Halaman Data Dosen

Halaman data dosen ini berfungsi untuk melihat data dosen serta menambah, merubah, dan menghapus data dosen.

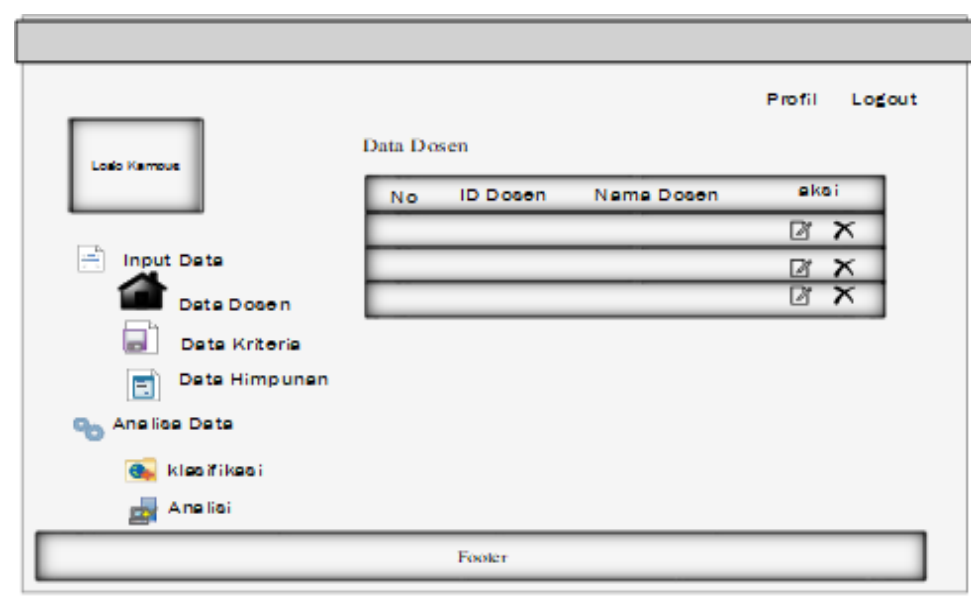

Gambar 5. Halaman data dosen

d. Halaman kriteria

Halaman data kriteria ini berfungsi untuk melihat data kriteria 


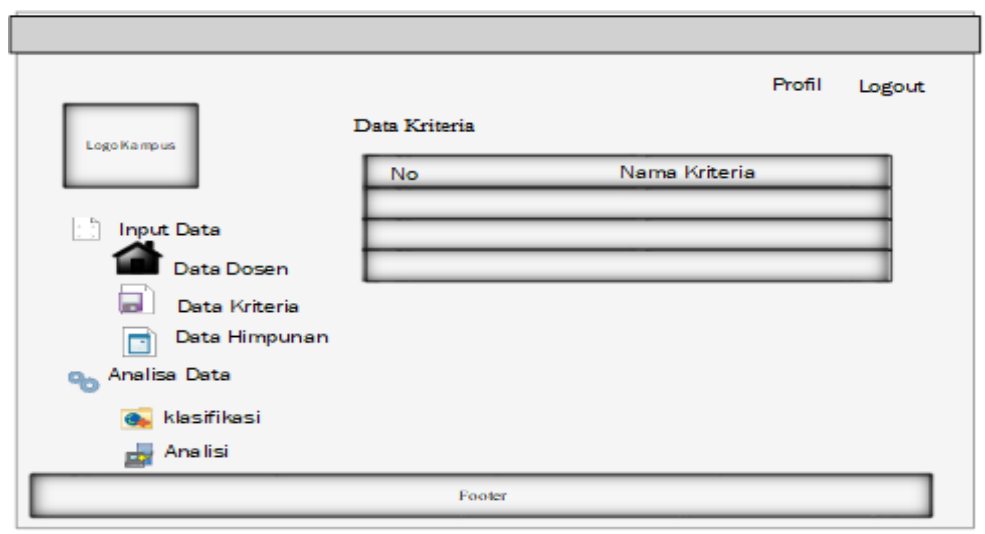

Gambar 6. Halaman kriteria

\section{SIMPULAN}

\subsection{Kesimpulan}

Berdasarkan penelitian dan pembahasan yang dilakukan, maka dapat disimpulkan beberapa hal sebagai berikut.

a. Pada penelitian ini sudah dikembangkan aplikasi sistem pendukung sistem pendukung keputusan untuk menentukan dosen favorit.

b. Dengan adanya aplikasi sistem pendukung keputusan ini dapat membantu pada STMIK mitra karya untuk lebih cepat mendapatkan nilai tertinggi untuk menentukan dosen favorit

c. Dalam aplikasi SPK ini menggunakan metode Fuzzy SAW (simple Addive weighting) untuk menghitug nilai bobot kriteria dan melakukan proses perangkingan. Dimana kriteria-kriteria tersebut diberi nilai bobot dan nilai bobot tersebut dinormalisasika kemudian perhitungan nilai bobot dan menghasilkan rangking tertinggi.

\subsection{Saran}

Berdasarkan pengujian yang telah dilakukan pada sistem pendukung keputusan yang telah dibuat, tentunya masih ada kekurangan dan kelemahan yang terjadi sehinggah perlu dikembangkan lagi agar kinerja lebih baik. Adapun saran untuk pengembangan penelitian ini adalah :

a. Penulis mengharapkan ada pihak atau peneliti lain yang mau mengembangkan dan melanjutkan penelitian ini.

b. Untuk menggunakan metode-metode SPK yang lain untuk membandingkan hasil keakuratan hasil keputusan tersebut.

c. Tersebut dinormalisasika dan menghasilkan rangking tertinggi.

\section{DAFTAR PUSTAKA}

[1] Afshari, Alireza., Mojahed, Majid., Mohd Yusuff, Rosnah. 2010. Simple Additive Weighting approach to Personnel Selection problem. International Journal of Innovation, Management and Technology, Vol. 1, No. 5, December 2010 ISSN: 2010-0248. 
[2] Carver, S.J., 1991. Integrating multi-criteria evaluation with geographical information systems. International Journal of Geographical Information Systems, 5 (3), 321-339. doi:10.1080/02693799108927858

[3] Fitriyani., Yuranda., Pajarini, Peti., Rosmawati. 2018. Penentuan Beasiswa Pada SMPN 6 Pangkalpinang Menggunakan Metode SAW dan Fuzzy Multi Attribute Decision Making. Jurnal RESTI (Rekayasa Sistem dan Teknologi Informasi) Vol . 2 No. 1 (2018) 437 - 443

[4] Hidayat, Awalludin. Mustafidah, Hindayati. Suyadi, Aman. Prosiding SENATEK 2015 Fakultas Teknik,:Penerapan Metode Simple Additive Weighting (Saw) Untuk Sistem Pendukung Keputusan Penilaian Kinerja Dosen Di Universitas Muhammadiyah Purwokerto. Universitas Muhammadiyah Purwokerto. Purwokerto, 28 November 2015, ISBN 978-602-14355-0 -2.

[5] Natalia, Christine., Triyanti, Vivi., Christin Pradina, Tri. 2016. Devising Decision Support System for the Selection of Medical Equipment Delivery Service. Journal of Industrial and Intelligent Information Vol. 4, No. 2, March 2016.

[6] Sihombing Hutasoit, Rotua. Perdana Windarto, Agus. Hartama, Dedy. Solikhun. JURASIK (Jurnal Riset Sistem Informasi \& Teknik Informatika): Sistem Pendukung Keputusan Pemilihan Guru Terbaik Pada Smk Maria Goretti Pematangsiantar Menggunakan Metode Simple Additive Weighting (Saw). Volume 1, Nomor 1, Juli 2016.

[7] Sri dan Purnomo Hari. 2010, "Aplikasi Logika Fuzzy", Cetakan Pertama, Graham Ilmu, Yogyakarta

[8] Z. Zhang., U. Demšar., J. Rantala., J. Rantala. 2014. A fuzzy multiple-attribute decisionmaking modelling for vulnerability analysis on the basis of population information for disaster management. International Journal of Geographical Information Science, 2014 Vol. 28, No. 9, 1922-1939. 9, http://dx.doi.org/10.1080/13658816.2014.908472 